\title{
Fragmentations of (E)- and (Z)- isomers of 2-methylbuten-1-yl(aryl) iodonium triflates: competing mechanisms for enol triflate formation
}

\author{
Robert J. Hinkle* and Ann M. Mikowski ${ }^{\dagger}$ \\ The Department of Chemistry, The College of William and Mary, \\ P. O. Box 8795, Williamsburg, VA 23187-8795 \\ Email: rjhink@wm.edu
}

This article is dedicated to Dr. Anastasios Varvoglis on the occasion of his $65^{\text {th }}$ birthday

(received 01 Apr 03; accepted 21 July 03; published on the web 25 July 03)

\begin{abstract}
We examined fragmentation reactions of $(E)$ - and (Z)-2-methylbuten-1-yl(aryl)iodonium triflates (aryl $\left.\left.=\mathrm{C}_{6} \mathrm{H}_{5^{-}}, 4-\left(\mathrm{CF}_{3}\right) \mathrm{C}_{6} \mathrm{H}_{4}, 3,5-\left(\mathrm{CF}_{3}\right)_{2} \mathrm{C}_{6} \mathrm{H}_{4}\right)^{-}\right)$to afford aryl idodides and six enol triflates. Four of these vinyl triflates involve alkyl migrations followed by triflate trapping of secondary vinyl cations whereas two do not involve migrations. Fragmentation rates in dry, neutral $\mathrm{CDCl}_{3}$ were determined as were the distributions of enol triflate products. The ratios of rate constants for the $(E)-/(Z)$ - isomers ranged between 5.0 and 8.5 and, in all salts, the rearranged enol triflate derived from migration of the alkyl moiety trans- to the aryliodonio- nucleofuge was observed in the greatest quantities. These data indicate that the fragmentation rates are significantly determined by the migratory aptitude of the trans- $\beta$-alkyl substituent and departure of the aryliodonionucleofuge occurs by anchimeric assistance. The ratios of inverted "unrearranged" enol triflate products were greater for the $(Z)$-isomers of the iodonium salt precursors indicating that steric effects play a role and implies that these inverted, unrearranged products are derived from inplane $\left(\sigma^{*}\right) \mathrm{S}_{N} 2$ reaction. The presence of the remaining, retained, unrearranged enol triflate can be explained by a ligand coupling mechanism $\left(\pi^{*} \mathrm{~S}_{N} 2\right)$ and the fragmentation mechanism(s) do not require the intermediacy of a primary vinyl cation.
\end{abstract}

Keywords: Vinyl cation, iodonium salt, ligand coupling, hypervalent iodine, vinyl iodonium, substitution

\section{Introduction}

Over the last several years, $\mathrm{we}^{1}$ as well as others ${ }^{2}$ have discussed primary cation involvement in fragmentation processes of vinylic hypervalent iodine salts. The phenyliodonio - moiety is an 
outstanding nucleofuge ${ }^{3}$ and both $\tilde{\beta}$ monosubstituted and $\beta$, $\beta$-disubstituted alkenyl(aryl)iodonium salts participate in both substitution and fragmentation reactions. Whereas Okuyama and coworkers have generally focused on chiral $^{2 \mathrm{~b}-\mathrm{c}}$ and $\beta, \beta$-disubstituted alkenyl(phenyl)iodonium tetrafluoroborate salts, ${ }^{2 a}$ we have investigated dialkyl substituted aryliodonium salts in which the aryl moieties commonly include one and/or two strongly electron-withdrawing trifluoromethyl groups. ${ }^{1}$ The current study examines the differences in reactivity between stereoisomeric pairs of salts containing three different aryl moieties (Figure 1).

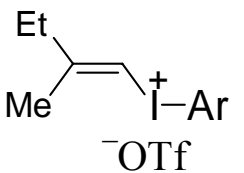

(E)-1a-c

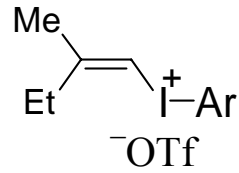

(Z)-1a-c

$$
\begin{aligned}
& \text { a: } \mathrm{Ar}=\mathrm{Ph} \\
& \text { b: } \mathrm{Ar}=4-\left(\mathrm{CF}_{3}\right) \mathrm{C}_{6} \mathrm{H}_{4^{-}} \\
& \text {c: } \mathrm{Ar}=3,5-\left(\mathrm{CF}_{3}\right)_{2}-\mathrm{C}_{6} \mathrm{H}_{3}-
\end{aligned}
$$

Figure 1. Salts used for fragmentation studies in $\mathrm{CDCl}_{3}$.

\section{Results and Discussion}

We synthesized six salts by established methods ${ }^{4,5}$ and examined the fragmentations of $(E)$ - and (Z)-2-methyl-1-butenyl(aryl)iodonium triflate salts, where aryl was phenyl, 4trifluoromethylphenyl, or bis-3,5-trifluoromethyl- phenyl ((E)- and (Z)-1a-c, Fig. 1). The fragmentation products of alkenyl(aryl)iodonium triflate salts include the aryl iodide and six enol triflate isomers; ${ }^{6}$ all of these have been identified by comparison to authentic samples using GC MS (as shown for the $(E)$-isomer in eq 1). The same seven products were also obtained upon fragmentation of the (Z)-isomer, albeit in different ratios (vide infra, Table 2).

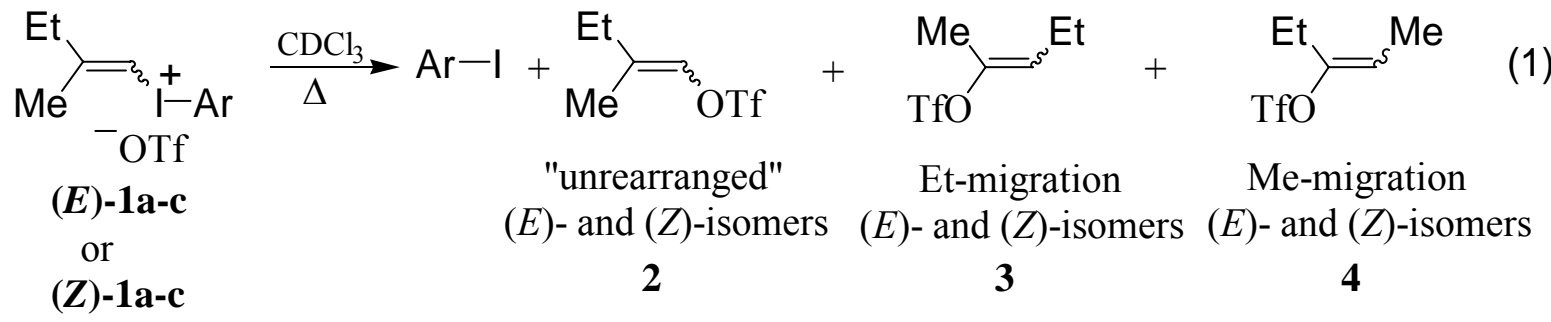

We utilized ${ }^{1} \mathrm{H}$ NMR spectroscopy with 1,2-dibromoethane as an internal standard to study the rate of fragmentation by observing the decrease in the ortho-proton resonances in the starting material and the increase in the ortho-proton resonances in the iodoarene fragmentation product 
(Ar-I) in the spectra. We then constructed first-order kinetic plots ( $\ln [\mathrm{A}] / \ln [\mathrm{A}]_{0}$ vs. time), and obtained rate constants for the fragmentations (Table 1).

Analysis of the reaction products was then performed by GC MS analysis of the samples resulting from the NMR-tube kinetics experiments. The samples were filtered through a short plug of silica gel using pentane as eluent and the solutions analyzed were compared to the authentic samples of enol triflate mixtures (Table 2). ${ }^{6}$ These data show that in the cases of the $(E)$ - isomers, a higher degree of ethyl migration indicates that the $\beta$-alkyl moiety trans- to the nuleofuge occurs to a greater extent than the group that is cis- (methyl). In the (Z)-isomers, a preponderance of migration of the group trans- to the aryliodonio- moiety (i.e., methyl) also occurs.

Table 1. Kinetic data for fragmentations of 2-methyl-1-butenyl(aryl)iodonium triflate salts in $\mathrm{CDCl}_{3}$

\begin{tabular}{|c|c|c|c|c|c|}
\hline Entry & Isomer & Salt & $\mathrm{Ar}$ & Temp $\left({ }^{\circ} \mathrm{C}\right)$ & $\mathrm{k} \times 10^{4}\left(\sec ^{-1}\right)$ \\
\hline 1 & \multirow{9}{*}{$(E)$} & $(E)-1 \mathbf{a}$ & $\mathrm{Ph}$ & 50 & 0.372 \\
\hline 2 & & $(E)-1 a$ & $\mathrm{Ph}$ & 55 & 0.651 \\
\hline 3 & & $(E)-1 \mathbf{a}$ & $\mathrm{Ph}$ & 60 & 1.38 \\
\hline 4 & & $(E)-1 b$ & $4-\mathrm{CF}_{3} \mathrm{C}_{6} \mathrm{H}_{4}$ & 30 & 0.109 \\
\hline 5 & & $(E)-1 b$ & $4-\mathrm{CF}_{3} \mathrm{C}_{6} \mathrm{H}_{4}$ & 40 & 0.485 \\
\hline 6 & & $(E)-1 b$ & 4- $\mathrm{CF}_{3} \mathrm{C}_{6} \mathrm{H}_{4}$ & 50 & 1.62 \\
\hline 7 & & $(E)-1 c$ & 3,5- $\left(\mathrm{CF}_{3}\right)_{2} \mathrm{C}_{6} \mathrm{H}_{3}$ & 30 & 0.722 \\
\hline 8 & & $(E)-1 c$ & $3,5-\left(\mathrm{CF}_{3}\right)_{2} \mathrm{C}_{6} \mathrm{H}_{3}$ & 40 & 2.12 \\
\hline 9 & & $(E)-1 c$ & $3,5-\left(\mathrm{CF}_{3}\right)_{2} \mathrm{C}_{6} \mathrm{H}_{3}$ & 45 & 3.89 \\
\hline 10 & \multirow{7}{*}{$(Z)$} & $(Z)-1 \mathbf{a}$ & $\mathrm{Ph}$ & 60 & 0.279 \\
\hline 11 & & $(Z)-1 b$ & 4- $\mathrm{CF}_{3} \mathrm{C}_{6} \mathrm{H}_{4}$ & 50 & 0.295 \\
\hline 12 & & $(Z)-1 b$ & $4-\mathrm{CF}_{3} \mathrm{C}_{6} \mathrm{H}_{4}$ & 55 & 0.561 \\
\hline 13 & & $(Z)-1 b$ & 4- $\mathrm{CF}_{3} \mathrm{C}_{6} \mathrm{H}_{4}$ & 60 & 1.27 \\
\hline 14 & & $(Z)-1 c$ & $3,5-\left(\mathrm{CF}_{3}\right)_{2} \mathrm{C}_{6} \mathrm{H}_{3}$ & 40 & 0.248 \\
\hline 15 & & $(Z)-1 c$ & $3,5-\left(\mathrm{CF}_{3}\right)_{2} \mathrm{C}_{6} \mathrm{H}_{3}$ & 50 & 1.50 \\
\hline 16 & & $(Z)-1 c$ & $3,5-\left(\mathrm{CF}_{3}\right)_{2} \mathrm{C}_{6} \mathrm{H}_{3}$ & 60 & 4.26 \\
\hline
\end{tabular}


Table 2. Relative percentages of fragmentation products of (E)- and (Z)-2-methyl-1butenyl(aryl)iodonium triflate salts in $\mathrm{CDCl}_{3}$ filtered through basic alumina

\begin{tabular}{|c|c|c|c|c|c|c|}
\hline Compound & $\mathrm{Ar}$ & Temp $\left({ }^{\circ} \mathrm{C}\right)$ & Me migration & Et migration & Retention $^{\mathrm{a}}$ & Inversion ${ }^{\mathrm{b}}$ \\
\hline$(E)-1 \mathbf{a}$ & $\mathrm{Ph}$ & 50 & 40 & 56 & 1.8 & 2.6 \\
\hline$(E)-1 a$ & $\mathrm{Ph}$ & 55 & 30 & 62 & 4.7 & 3.5 \\
\hline$(E)-1 \mathbf{a}$ & $\mathrm{Ph}$ & 60 & 43 & 54 & 0.9 & 2.1 \\
\hline$(E)-1 b$ & 4- $\mathrm{CF}_{3} \mathrm{C}_{6} \mathrm{H}_{4}$ & 30 & 20 & 69 & 3.7 & 4.4 \\
\hline$(E)-1 b$ & $4-\mathrm{CF}_{3} \mathrm{C}_{6} \mathrm{H}_{4}$ & 40 & 28 & 64 & 3.5 & 4.3 \\
\hline$(E)-1 b$ & 4- $\mathrm{CF}_{3} \mathrm{C}_{6} \mathrm{H}_{4}$ & 50 & 39 & 53 & 5.5 & 5.3 \\
\hline$(E)-1 \mathrm{c}$ & $3,5-\left(\mathrm{CF}_{3}\right)_{2} \mathrm{C}_{6} \mathrm{H}_{3}$ & 30 & 21 & 73 & 3.6 & 2.3 \\
\hline$(E)-1 \mathrm{c}$ & $3,5-\left(\mathrm{CF}_{3}\right)_{2} \mathrm{C}_{6} \mathrm{H}_{3}$ & 40 & 43 & 53 & 2.0 & 1.8 \\
\hline$(E)-1 \mathrm{c}$ & $3,5-\left(\mathrm{CF}_{3}\right)_{2} \mathrm{C}_{6} \mathrm{H}_{3}$ & 45 & 18 & 69 & 4.8 & 8.3 \\
\hline (Z)-1a & $\mathrm{Ph}$ & 60 & 40 & 23 & 5.9 & 32 \\
\hline$(Z)-1 b$ & $4-\mathrm{CF}_{3} \mathrm{C}_{6} \mathrm{H}_{4}$ & 50 & 50 & 32 & 3.1 & 15 \\
\hline$(Z)-1 b$ & $4-\mathrm{CF}_{3} \mathrm{C}_{6} \mathrm{H}_{4}$ & 55 & 50 & 31 & 3.2 & 16 \\
\hline$(Z)-1 b$ & $4-\mathrm{CF}_{3} \mathrm{C}_{6} \mathrm{H}_{4}$ & 60 & 47 & 24 & 6.3 & 23 \\
\hline$(Z)-1 c$ & $3,5-\left(\mathrm{CF}_{3}\right)_{2} \mathrm{C}_{6} \mathrm{H}_{3}$ & 40 & 52 & 29 & 5.3 & 14 \\
\hline$(Z)-1 c$ & $3,5-\left(\mathrm{CF}_{3}\right)_{2} \mathrm{C}_{6} \mathrm{H}_{3}$ & 50 & 51 & 35 & 4.4 & 9.6 \\
\hline$(Z)-1 c$ & $3,5-\left(\mathrm{CF}_{3}\right)_{2} \mathrm{C}_{6} \mathrm{H}_{3}$ & 60 & 54 & 33 & 3.3 & 9.4 \\
\hline
\end{tabular}

${ }^{\text {a }}$ Retention refers to the resulting enol triflate in which the OTf moiety is in the same relative position as the iodoaryl moiety in the starting material.

${ }^{\mathrm{b}}$ Inversion refers to the resulting enol triflate in which the OTf moiety is in the opposite relative position as the iodoaryl moiety in the starting material.

Four mechanisms have been discussed with regard to fragmentation mechanisms leading to the six enol-triflate isomers: (a) $\mathrm{S}_{N} 1$ departure of the aryliodonio moiety to provide a primary vinyl cation, $A$; (b) in-plane $\mathrm{S}_{N} 2$ reaction (c) out-of-plane $\mathrm{S}_{N} 2$ reaction also termed "ligand coupling;" and; (d) concerted alkyl migration and aryliodonio- nucleofuge departure. These mechanisms are shown, respectively in Schemes 1-4. Both $\mathrm{we}^{1 \mathrm{~b}-\mathrm{c}}$ and the Okuyama group ${ }^{7}$ had reported rearrangement products that could have occurred by $S_{N} 1$ fragmentation of various iodonium salts. If an $\mathrm{S}_{N} 1$ process were operative, it would lead to a primary vinyl cation, $\mathbf{A}$, that could be trapped by triflate directly to form $(E)$ - and $(Z)$-2. Migration of a $\beta$-alkyl group before trapping would then provide a more stable secondary vinyl cation $(\mathbf{B}$ and/or $\mathbf{C}$ in Scheme 4, vide infra) that could then be trapped to provide mixtures of $(E)$ - and (Z)-3 as well as (E)- and (Z)-4. For the linear primary cation, both unrearranged isomers $(E)$ - and $(Z)-2$ should be produced in approximately equal ratios. Further, migration of either $\beta$-alkyl moiety in $\mathbf{B}$ should be equally facile in a free cation and isomers of $\mathbf{3}$ and $\mathbf{4}$ should also be present in approximately equal ratios. 


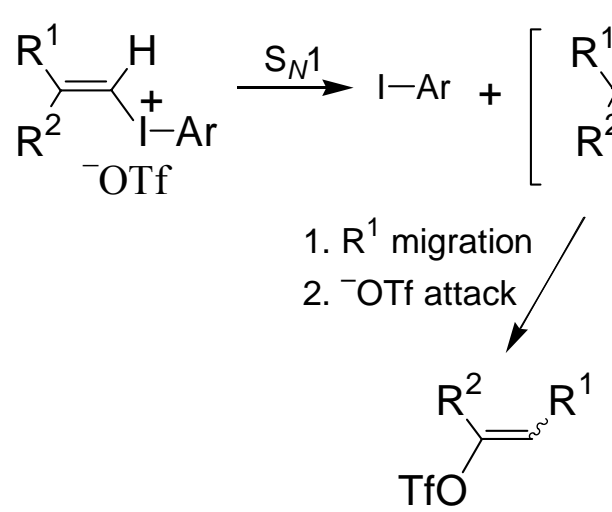

$(E)-$ and $(Z)-3$

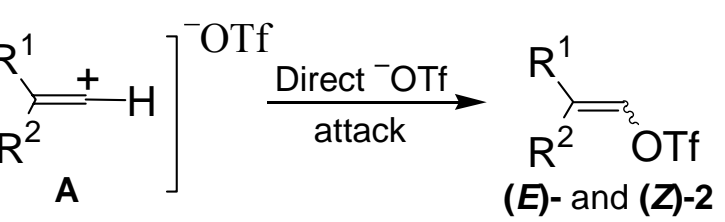

1. $R^{2}$ migration

2. ${ }^{-} \mathrm{OTf}$ attack

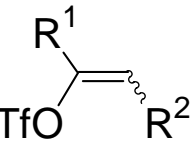

(E)- and (Z)-4

\section{Scheme 1}

Detection of "unrearranged" isomers (e.g., (E)- and (Z)-2) in varying ratios as well as products developed by alkyl shifts were believed to provide evidence for primary vinyl cation formation. ${ }^{1 \mathrm{~b}-\mathrm{c}, 7}$ However, competing, alternative mechanisms (i.e., Schemes 2 and 3, vide infra) could also account for the unrearranged products. Strong support for this assertion has been provided by Fujita and co-workers' descriptions of fragmentations of chiral 4methylcyclohexylidenyl(aryl)iodonium salts ${ }^{1 \mathrm{~b}-\mathrm{c}}$ as well as the data presented herein.

An in-plane $\mathrm{S}_{N} 2$ mechanism has been documented to proceed with weakly basic nucleophiles such as bromide ion. ${ }^{8,9}$ This process leads to complete inversion at the $\alpha$-carbon and is supported by computational studies using MP2 calculations with polarized double-zeta basis sets. ${ }^{7 \mathrm{~b}}$

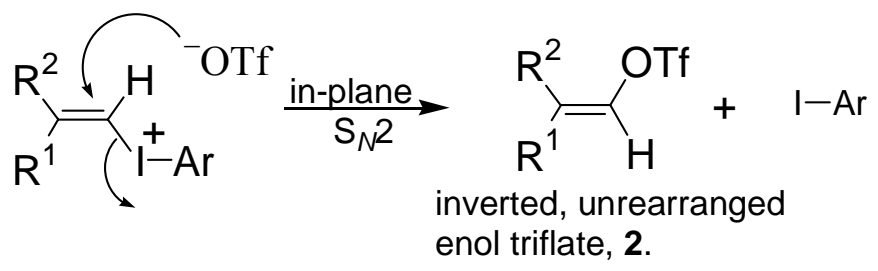

\section{Scheme 2}

A third mechanism has been studied computationally, is possible for iodonium salts and is sometimes referred to as ligand coupling (LC). ${ }^{7 b, 8,10}$ The nucleophile (triflate counter ion this our case) attacks the $\pi^{*}$ orbital at the $\alpha$-carbon perpendicular to the plane defined by the alkene; this leads to displacement of the aryliodonio- moiety and net retention of configuration in the unrearranged product (e.g., product 2). As was found for acetate, the triflate counter ion likely is involved in partial coordination with the iodine, forming a $\lambda^{3}$-iodane complex ${ }^{2 c, 7,8}$ and reductive elimination occurs to form the retained, unrearranged enol triflate, 2, as well as the aryl iodide byproduct. 


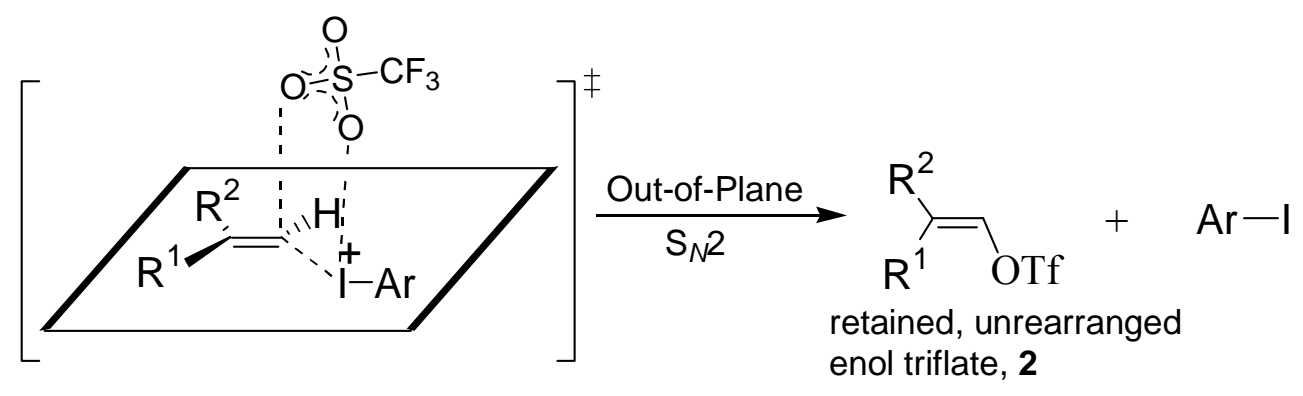

\section{Scheme 3}

The fourth mechanism (Scheme 4) related to the $S_{N} 1$ process involves departure of the aryliodonio- moiety in which there is concerted migration of the trans-alkyl group. The concerted migration results in the direct formation of a linear secondary vinyl cation (e.g., A or $\mathbf{B}$ in Scheme 4), that is attacked by the triflate counter ion; this results in two of the four "rearranged" triflate isomers $(\boldsymbol{E})$ - and $(\boldsymbol{Z})-\mathbf{3}$ from Et migration in (E)-1a-c). This mechanism also avoids the high energy primary vinyl cation as an intermediate. The resulting secondary vinyl cation can also undergo a rapid [1,2] hydride shift, ${ }^{11}$ which would provide another secondary vinyl cation, $\mathbf{C}$; this linear cation is also attacked from both sides by triflate, resulting in two additional "rearranged" isomers.

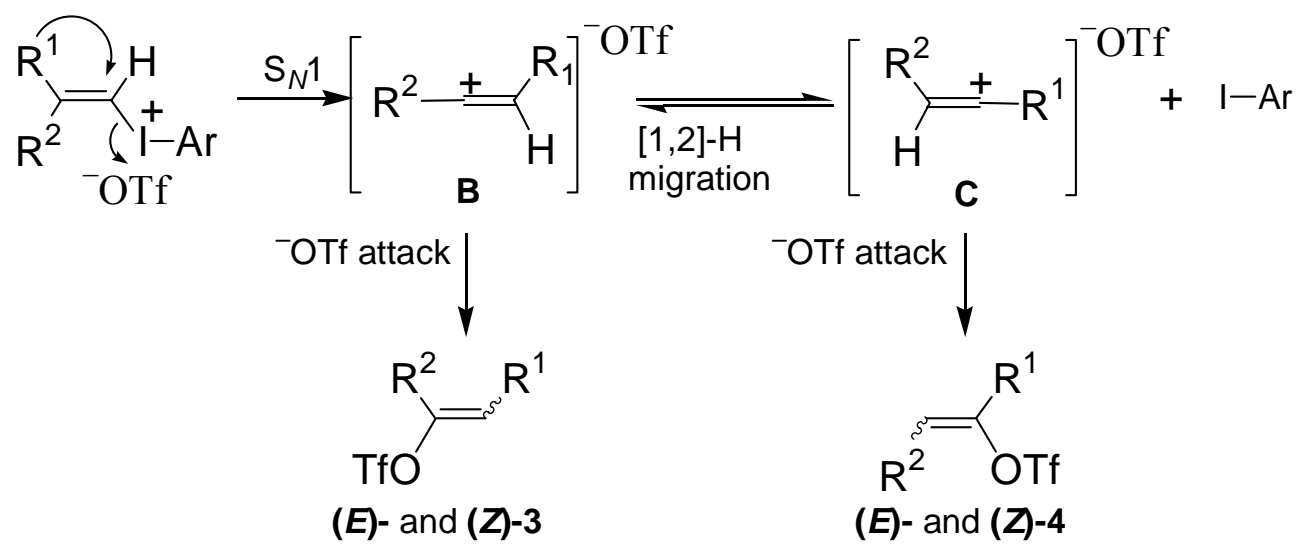

\section{Scheme 4}

Comparison of the fragmentation rates of $(E)$ - and $(Z)$ - isomers in clearly shows that when the ethyl moiety is trans- to the aryliodonio- nucleofuge, fragmentation is significantly more facile (Table 3). We have found this same effect in earlier studies of alkenyl(aryl)iodonium salts containing larger $\beta$-alkyl groups. ${ }^{\text {la }}$

Table 3. Ratios of reaction rates between the $(E)$ - and $(Z)$-isomers

Ar $\quad$ Temp $\left({ }^{0} \mathrm{C}\right) \quad \mathrm{k}(E) / \mathrm{k}(Z)$




\begin{tabular}{ccc}
\hline $\mathrm{Ph}$ & 60 & 5.0 \\
$4-\mathrm{CF}_{3} \mathrm{C}_{6} \mathrm{H}_{4}$ & 50 & 5.8 \\
$3,5-\left(\mathrm{CF}_{3}\right)_{2} \mathrm{C}_{6} \mathrm{H}_{3}$ & 40 & 8.5 \\
\hline
\end{tabular}

A Hammett plot was constructed for the (Z)-isomers using the fragmentation of (Z)-2Methyl-1-butenyl(phenyl)iodonium triflate as the reference equation. The sigma values for the meta- and para- $\mathrm{CF}_{3}$ - substituents are 0.54 and $0.86,{ }^{12}$ respectively. ${ }^{13} \mathrm{~A} \rho$ value of 1.4 indicates that the fragmentation is facilitated by electron withdrawing groups. This is clear in that the 4trifluoromethylphenyl substituted isomer has a lower rate constant than the 3,5-trifluoromethylphenyl analog because the extra electron withdrawing group in the latter increases iodine's effective positive charge thus increasing the nucleofugality of the aryliodonio- moiety.

The activation parameters (Table 4) for the salts in this study also provide evidence for the fourth mechanism involving neighboring group participation in the fragmentations. The $\Delta H^{*}$, and $\Delta G^{\ddagger}$ values are both also consistent with fragmentation reactions occurring slightly above ambient temperatures. The $E_{a}$ values for both isomers reflect the greater nucleofugality of the aryl rings containing one and two trifluoromethyl groups. The activation energies of the $(Z)$ isomers are greater than the activation energies for the $(E)$-isomers. This is consistent with anchimeric assistance of the trans- $\beta$-alkyl moiety and alkyl migration favors groups that can better stabilize a positive charge, e.g., Et $>\mathrm{Me}>\mathrm{H}^{14}$ The calculated entropies of activation for the $(E)$-salts 1a-c decreased with increasing electron-withdrawing character present in the aryliodonio- moiety. The $(Z)$-isomer, however, showed an increase in entropy of activation when a second $\mathrm{CF}_{3}$ - group was present in the aromatic ring. At present, we do not know the source of this phenomenon, but $\Delta S^{\dagger}$ for enol triflates varied according to substitution and solvent ${ }^{15}$ and our numbers were determined over a somewhat narrow temperature range.

Table 4. Activation parameters for salts used in this study

\begin{tabular}{cccccc}
\hline Compound & $\mathrm{Ar}$ & $\mathrm{E}_{\mathrm{a}}(\mathrm{kcal} / \mathrm{mol})$ & $\Delta H^{*}(\mathrm{kcal} / \mathrm{mol})$ & $\Delta G^{*}(\mathrm{kcal} / \mathrm{mol})$ & $\Delta S^{*}(\mathrm{kcal} / \mathrm{mol})$ \\
\hline $\boldsymbol{( E ) - 1 a}$ & $\mathrm{Ph}$ & 28.0 & 27.4 & 27.2 & 5.8 \\
$(\boldsymbol{E})-\mathbf{1 b}$ & $4-\mathrm{CF}_{3} \mathrm{C}_{6} \mathrm{H}_{4}$ & 26.3 & 26.3 & 25.3 & 3.6 \\
$(\boldsymbol{E})-1 \mathbf{c}$ & $3,5-\left(\mathrm{CF}_{3}\right)_{2} \mathrm{C}_{6} \mathrm{H}_{3}$ & 21.3 & 20.7 & 23.5 & -9.2 \\
$(\boldsymbol{Z})-1 \mathbf{b}$ & $4-\mathrm{CF}_{3} \mathrm{C}_{6} \mathrm{H}_{4}$ & 31.2 & 30.6 & 30.1 & 1.8 \\
$(\boldsymbol{Z})-1 \mathbf{1 c}$ & $3,5-\left(\mathrm{CF}_{3}\right)_{2} \mathrm{C}_{6} \mathrm{H}_{3}$ & 29.6 & 29.0 & 25.1 & 12.9 \\
\hline
\end{tabular}

The relative proportion of rearranged products in the current study is lower than in the previous study. ${ }^{1 a}$ We attribute this to two effects: (a) the lower steric requirements for $\sigma^{*}$ and $\pi^{*}$ $\mathrm{S}_{N} 2$ processes with these smaller alkyl groups at the $\beta$-position and (b) the smaller alkyl groups do not contribute as much electron density to the developing secondary cation (i.e., $\mathbf{B}$ and $\mathbf{C}$ in Scheme 4) and thus slightly decrease their stability. In the previous studies, the alkyl groups 
were butyl and ethyl rather than methyl and ethyl and these larger salts fragmented at significantly lower temperatures. ${ }^{\text {la-b }}$

In terms of the rearranged products (i.e., 3 and 4), the comparative proportion of (E)- $\beta$-alkyl vs. (Z)- $\beta$-alkyl migration does, however, have the potential to be misleading since the transition state for hydride migration between the resulting secondary vinyl cations, $\mathbf{D}$ and $\mathbf{E}$ (eq 2) was calculated to lie $0.32 \mathrm{kcal} / \mathrm{mole}$ above the secondary cations in the case of 2-butenyl cations (eq 2). ${ }^{11}$

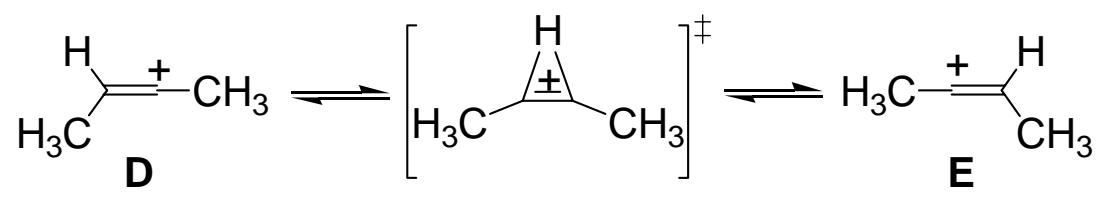

\section{Conclusions}

We have studied the fragmentations of (E)- and (Z)-2-methylbuten-1-yl-(aryl)iodonium triflate salts in $\mathrm{CDCl}_{3}$ by using ${ }^{1} \mathrm{H}$ NMR spectroscopy. The fragmentation products include aryl iodide and six enol triflate isomers. The significantly increased fragmentation rate of the $(E)-2-$ methylbuten-1-yl(aryl)iodonium salt isomers vs. the corresponding $(Z)$-isomers as well as the increased quantities of inverted, unrearranged enol triflate products for the less hindered, $(Z)$ isomers, the reaction manifold involving a primary vinyl cation is unlikely. If occurring via simple $\mathrm{S}_{N} 1$ process, there should be no difference in fragmentation rates between the two isomers and the relative ratios of unrearranged isomers would not vary. Three mechanisms including both in-plane ( $\sigma^{*}$ attack) and out-of-plane ( $\pi^{*}$ attack) $\mathrm{S}_{N} 2$ as well as concerted trans$\beta$-alkyl shift and aryliodonio- departure account for the formation of all the enol triflate products. The positive Hammet $\rho$-value is also consistent with anchimeric assistance, the preponderance of trisubstituted enol triflate isomers derived from $\beta$-trans-alkyl migration and literature experiments provide support for the aforementioned mechanisms. Secondary deuterium kinetic isotope effect measurements are now being conducted to evaluate the extent to which alkylidenecarbenes are involved in the formation of unrearranged enol triflate products. Preliminary data indicate that the isotope effect could be primary rather than secondary. This implies a significant contribution from a fifth mechanism involving $\alpha$-deprotonation and intermediacy of an alkylidenecarbene.

\section{Experimental Section}

General Procedures. All reactions were carried out under nitrogen atmosphere. Dichloromethane was distilled from $\mathrm{CaH}_{2}$. Pentane, ethyl acetate, acetonitrile, hydrogen 
peroxide and magnesium sulfate were purchased from Fisher and used as received unless otherwise noted. Deuterated chloroform, trimethylsilylcyanide, dimethyl sulfide, copper(I) bromide-dimethyl sulfide, tri- $n$-butyl-stannane, methyl magnesium bromide, ethyl magnesium bromide, tetramethylene-diamine, and 2-iodosobenzoic acid were purchased from Aldrich Chemical Company. Trifluoroacetic anhydride, 1-iodo-3,5-bis(trifluoromethyl)benzene and 4iodobenzotrifluoride were purchased from Acros and used as received. Anhydrous ether was purchased from J.T. Baker, 1-propyne and butyne from GFS Chemicals and nitrogen from Air Products. The salts examined in this study were synthesized by common methods that we have utilized previously. ${ }^{1 \mathrm{a}-\mathrm{c}, 4,5}$ Salts $(E)$ - and $(Z)$-1a were previously reported, ${ }^{4}(Z)-1 \mathrm{~b}$ and $(Z)-1 \mathrm{c}$ were recently described by X-ray, ${ }^{5}$ and $(E)-1 \mathrm{~b}$ and $(E)-1-c$ are described herein.

All NMR spectroscopic data were obtained using a Varian Mercury $400 \mathrm{MHz}$ nuclear magnetic resonance spectrometer and chemical shifts are reported in ppm downfield from TMS and referenced to residual protons from the NMR solvent $\left(\delta=7.26\right.$ and 77.0 for ${ }^{1} \mathrm{H}$ and ${ }^{13} \mathrm{C}$, respectively in $\mathrm{CDCl}_{3}$ ). IR spectra were obtained on a Perkin-Elmer 1600 FTIR using $\mathrm{NaCl}$ plates purchased from International Crystal Laboratories. GC-MS traces were recorded on a Hewlett-Packard 5890 Series II Gas Chromatograph with an Ultra-1 crosslinked (methyl silicone gum; $12 \mathrm{~m} \times 0.2 \mathrm{~mm} \times 0.33 \mu \mathrm{m})$ column, equipped with a $70 \mathrm{eV} \mathrm{HP} 5971 \mathrm{~A}$ mass selective detector. Melting points were obtained on a Hoover Thomas Uni-Melt ${ }^{\circledR}$ capillary melting point device or a MelTemp ${ }^{\circledR}$ apparatus and are uncorrected.

\section{Experimental procedure for kinetic runs}

Chloroform- $d(0.5 \mathrm{~mL})$ was filtered through basic alumina to remove any acidic impurities and placed in an oven-dried NMR tube. The probe on the spectrometer was heated to the specific temperature and the chloroform was allowed to equilibrate to the probe's temperature for 15 minutes. Then ca. 14-18 mg of salt and $2 \mu \mathrm{L}$ of dibromoethane, were added to the heated chloroform. The NMR tube was placed back into the probe and the sample was allowed to return to the temperature for about 5 minutes, at which time the collection of data was begun. The duration of data collection lasted from 3.5 to 11 hours, depending on reactivities of the salts. After the experiment ended the mixture was placed into a $20 \mathrm{~mL}$ scintillation vial that was stored in a refrigerator at $15^{\circ} \mathrm{C}$.

The rate constants $(\mathrm{k})$ were determined from the slope of the first-order rate law plot: In $[\mathrm{A}]_{\mathrm{r}} /[\mathrm{A}]_{\mathrm{o}}$ vs. time. The concentration at time $\mathrm{t}\left([\mathrm{A}]_{\mathrm{t}}\right)$ was determined by the relative integration of the starting material to that of the internal standard. The time plotted was considered to be halfway through the pulse sequence for each spectrum (e.g., for 96 pulses ( $5 \mathrm{~min} 0 \mathrm{~s}$ ), halfway was considered to be 48 pulses $(2 \min 30 \mathrm{~s})$ ). Any rate constants taken from plots with an $\mathrm{R}^{2}$ value exceeding 0.9500 and a rate constant within $10 \%$ of the other values were used in determining the average rate constant at each temperature.

\section{General procedure for the preparation of alkenyl(aryl)iodonium triflates}

Distilled $\mathrm{CH}_{2} \mathrm{Cl}_{2}(5 \mathrm{~mL})$ and cyano(aryl)iodonium triflate $(0.27 \mathrm{mmol})$ were placed in an ovendried $100 \mathrm{~mL}$ round bottom flask equipped with a stir bar and $\mathrm{N}_{2}$ inlet. The flask was placed in 
an acetonitrile/dry-ice cooling bath and the temperature lowered to $-40{ }^{\circ} \mathrm{C}$. The alkenyl tri- $n$ butylstannane $^{4 \mathrm{~b}}$ (1.1-1.3 equiv.) was then added via syringe. The reaction mixture was warmed until homogeneity was achieved at which time $\mathrm{Et}_{2} \mathrm{O}$ (ca. $5 \mathrm{~mL}$ ) was added and, with rapid stirring, an excess of hexanes was added until the solution became turbid. Cooling overnight to $15{ }^{\circ} \mathrm{C}$ afforded white, crystalline solids in $40-90 \%$ yields.

Representative example. Preparation of $(E)$-2-methyl-1-butenyl(4-trifluoromethylphenyl)iodonium triflate ((E)-1b). (E)-2-Methyl-1-butenyl(4-trifluoromethylphenyl) iodonium triflate $(\boldsymbol{E})-\mathbf{1 b}$ was prepared via the general procedure from cyano(4trifluoromethylphenyl)iodonium triflate, $13(0.401 \mathrm{~g}, 0.897 \mathrm{mmol})$, and $(E)$-2-methyl-1-propenyl tri- $n$-butylstannane ${ }^{4 \mathrm{~b}}(0.387 \mathrm{~g}, 1.08 \mathrm{mmol})$. The product was isolated as a white, crystalline solid

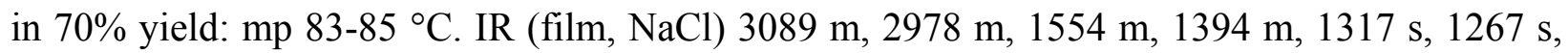
$1156 \mathrm{~s}, 1139 \mathrm{~s}, 1081 \mathrm{~s}, 1028 \mathrm{~s}, 1000 \mathrm{~s}, 828 \mathrm{~m}, 739 \mathrm{~s}, 639 \mathrm{~s}, \mathrm{~cm}^{-1} .{ }^{1} \mathrm{H} \mathrm{NMR}\left(\mathrm{CDCl}_{3}, 400 \mathrm{MHz}\right)$ $\delta 8.09(\mathrm{~d}, J=8.8 \mathrm{~Hz}, 2 \mathrm{H}), 7.69(\mathrm{~d}, J=8.8 \mathrm{~Hz}, 2 \mathrm{H}), 6.78(\mathrm{~s}, 1 \mathrm{H}), 2.50(\mathrm{q}, \mathrm{J}=7.3 \mathrm{~Hz}, 2 \mathrm{H}), 2.17$ (s, $3 \mathrm{H}), 1.12(\mathrm{t}, J=7.3 \mathrm{~Hz}, 3 \mathrm{H}) .{ }^{13} \mathrm{C}\left(\mathrm{CDCl}_{3}, 100 \mathrm{MHz}\right) \delta 163.5,134.6,134.0,128.2,114.8,94.7$, 32.6, 24.8, 12.2. Anal calcd for $\mathrm{C}_{13} \mathrm{H}_{13} \mathrm{~F}_{6} \mathrm{IO}_{3} \mathrm{~S}$ : C, 31.85; H, 2.67; S, 6.54. Found: C, 31.64; H, 2.73; S, 6.63.

Preparation of (E)-2-methylbuten-1-yl(3,5-bis(trifluoromethyl)phenyl)iodonium triflate ((E)-1c). This salt was prepared by the general procedure using cyano(3,5bis(trifluoromethyl)iodonium triflate, $(0.401 \mathrm{~g}, 0.779 \mathrm{mmol})$, and (E)-2-methyl-1-propenyl tri- $n$ butylstannane $^{4 \mathrm{~b}}(0.336 \mathrm{~g}, 0.934 \mathrm{mmol})$. The product was isolated as a white, crystalline solid in $48 \%$ yield (0.211g): $\mathrm{mp} 67-6{ }^{\circ} \mathrm{C}$. IR (film, NaCl) $3067 \mathrm{~s}, 2978 \mathrm{~s}, 1622 \mathrm{~m}, 1461 \mathrm{~m}, 1378 \mathrm{~m}$, 1344 s, 1278 s, 1167 s, 1139 s, 1028 s, 889 s, 694 s, 633 s. ${ }^{1} \mathrm{H}$ NMR $\left(\mathrm{CDCl}_{3}, 400 \mathrm{MHz}\right) .8 .40$ (s, $2 \mathrm{H}), 8.04(\mathrm{~s}, 1 \mathrm{H}), 6.87(\mathrm{~s}, 1 \mathrm{H}), 2.52(\mathrm{q}, J=7.3 \mathrm{~Hz}, 2 \mathrm{H}), 2.20(\mathrm{~s}, 3 \mathrm{H}), 1.13$ (t, $J=7.3 \mathrm{~Hz}, 3 \mathrm{H})$. Anal calcd for $\mathrm{C}_{14} \mathrm{H}_{12} \mathrm{~F}_{9} \mathrm{IO}_{3} \mathrm{~S}$ : C, 30.12; H, 2.17; S, 5.74. Found: C, 30.39; H, 2.29; S, 5.77.

Preparation of enol triflates, $(E)$ - and $(Z)$-2-methylbuten-1-yl triflate. An oven-dried $500 \mathrm{~mL}$ round bottomed flask was equipped with a stir bar and charged with $\mathrm{CH}_{2} \mathrm{Cl}_{2}(370 \mathrm{~mL})$, and 2,6di-tert-butylmethylpyridine $(2.258 \mathrm{~g}, 11.0 \mathrm{mmol})$. Triflic anhydride $(1.80 \mathrm{~mL}, 10.7 \mathrm{mmol})$ and 2methylbutyraldehyde $(0.855 \mathrm{~g}, 9.93 \mathrm{mmol})$ were added and the reaction mixture stirred overnight (ca. 12h). The solvent was removed in vacuo to afford a thick suspension of 2,6-di-tertbutylmethylpyridinium $\bullet \mathrm{TfOH}$ and pentane $(125 \mathrm{~mL})$ was added to the suspension. The pyridinium salt was collected on a fritted funnel and the filtrate concentrated in vacuo. Shortpath distillation of the concentrated filtrate afforded two fractions containing the two known, ${ }^{6 \mathrm{~b}}$ desired triflate stereoisomers. Formation of these vinyl triflates was verified by ${ }^{1} \mathrm{H} N M R$ spectroscopy as well as GC MS $\left(\mathrm{M}^{+}=218\right)$.

Preparation of $(E)$ - and (Z)-2-penten-3-yl triflates (methyl migration products). An inseparable mixture of these triflates was synthesized from 3 -pentanone $(0.77 \mathrm{~mL}, 7.6 \mathrm{mmol})$, 2,6-di-tert-butylmethylpyridine $(1.72 \mathrm{~g}, 8.36 \mathrm{mmol})$ and triflic anhydride $(1.36 \mathrm{~mL}, 8.08 \mathrm{mmol})$. Isolation by kugelroehr distillation afforded the known isomers ${ }^{15}$ which were dissolved and stored in pentane (GC MS, $(Z)$ - and (E)-isomers with stereochemistry of isomers not determined, $\left.\mathrm{M}^{+}=218\right)$. 
Preparation of $(E)$ - and $(Z)-2-p e n t e n-2-y l$ triflates (ethyl migration products). A mixture of the ethyl migration products was synthesized from 2-pentanone (1.20 mL, $10.9 \mathrm{mmol}), 2$,6-ditert-butylmethylpyridine $(2.442 \mathrm{~g}, 11.9 \mathrm{mmol})$ and triflic anhydride $(1.95 \mathrm{~mL}, 11.6 \mathrm{mmol})$. Isolation by kugelroehr distillation afforded the known isomers ${ }^{15}$ which were dissolved and stored in pentane. The isomers were not separated (GC MS, (Z)- and (E)-isomers with stereochemistry of isomers not determined, $\mathrm{M}^{+}=218$ ).

\section{Acknowledgements}

We are grateful to the Research Corporation (Grant CC4659), the NSF (CAREER Award: CHE9983863) and the Arnold and Mabel Beckman Foundation (scholarship for AMM) for support of this work.

\section{References and Notes}

* Author to whom correspondence should be addressed: rjhink@wm.edu.

$\dagger$ Current Address: Dept. of Chemistry, The University of Virginia, McCormick Road, P. O. Box 400319, Charlottesville, VA 22904-4319.

1. (a) McNeil, A. M.; Hinkle, R.J.; Rouse, E. A.; Thomas, Q. A.; Thomas, D. B. J. Org. Chem. 2001, 66, 5556. (b) Hinkle, R.J.; McNeil, A. M.; Thomas, Q. A.; Thomas, D. B. J. Am. Chem. Soc. 1999, 122, 3361. (c) Hinkle, R. J.; Thomas, D. B. J. Org. Chem. 1997, 62, 7534

2. (a) Okuyama, T.; Acc. Chem. Res. 2002, 35, 12 and refs therein. (b) Fujita, M.; Sakanishi, M.; Nishii, M.; Yamataka, H.; Okuyama, T. J. Org. Chem. 2002, 67, 8138 and refs therein. (c) Fujita, M.; Sakanishi, Y.; Nishii, M.; Yamataka, H.; Okuyama, T. J. Org. Chem. 2002, 67, 8130 and refs therein. (d) Okuyama, T.; Sato, K.; Ochiai, M. Bull. Chem. Soc. Jpn. 2000, $73,2341$.

3. Solvolysis experiments of 4-tert-butylcyclohexenyl(phenyl)iodonium tetrafluoroborate showed that rate of solvolysis exceeded that of the corresponding triflate by $10^{6}$. See, Okuyama, T.; Takino, T.; Sueda, T.; Ochiai, M. J. Am. Chem. Soc. 1995, 117, 3360.

4. (a) Zhdankin, V. V.; Scheuller, M. C.; Stang, P. J. Tetrahedron Lett. 1993, 34, 6853. (b) Hinkle, R. J.; Stang, P. J. Synthesis 1994, 313.

5. For X-ray structural analysis and synthesis of three (Z)-2-methyl-1-butenyl(aryl)iodonium salts, see: Hinkle, R. J.; McDonald, R. Acta Cryst., C. 2002, C58, 117.

6. Authentic samples of enol triflate mixtures were synthesized by standard methods. See, (a) Stang, P. J.; Treptow, W. Synthesis 1980, 283. (b) Stang, P. J.; Mangum, M. G.; Fox, D. P.; Haak, P. J. Am. Chem. Soc., 1974, 96, 4562. 
7. (a) Okuyama, T.;Sato, K.; Ochiai, M. Chem. Lett. 1998, 1177. (b) Okuyama, T.; Yamataka, H.; Ochiai, M. Bull. Chem. Soc. Jpn. 1999, 72, 2761.

8. (a) Okuyama, T.; Sato, K.; Ochiai, M. "Reactions of 2,2-Dialkylvinyl Iodonium Salt with Halide Ions," Bull. Chem. Soc. Jpn. 2000, 73, 2341. (b) Okuyama, T.; Takino, T.; Sado, K.; Ochiai, M. J. Am. Chem. Soc. 1998, 120, 2275.

9. A recent paper described $\sigma^{*}$ and $\pi^{*}$ attack of nucleophiles on vinylic systems: Bach, R. D.; Baboul, A. G.; Schlegel, H. B. J. Am. Chem. Soc. 2001, 123, 5787-5793.

10. Okuyama, T.; Yamataka. Can. J. Chem. 1999, 77, 577.

11. Okuyama et al. found that the transition state for hydride migration in the 2-buten-1-yl cation was only $0.32 \mathrm{kcal} / \mathrm{mole}$ above the energy of the secondary cations. See ref. $7 \mathrm{~b}$.

12. The value for the meta- substituent (0.86) was derived by multiplying the $\sigma$-meta value $(0.43)$ by two as described by Hammet. Hammet, L. P., Physical Organic Chemistry, $2^{\text {nd }}$ Edn; McGraw-Hill: New York, 1970; p 367.

13. Lowry, T. H.; Richardson, K. Schueller. Mechanisms and Theory in Organic Chemistry. Addison-Wesley: Boston, 2000; pp143-146.

14. Miller, B. Advanced Organic Chemistry: Reactions and Mechanisms, Prentice-Hall: New Jersey, 1998, pp 140-142.

15. Summerville, R. H.; Senkler, C. A.; Schleyer, P. v. R. Dueber, T. E.; Stang, P. J. J. Am. Chem. Soc. 1974, 96, 1100. 